University of Nebraska - Lincoln

DigitalCommons@University of Nebraska - Lincoln

8-1967

\title{
Development and Vasculature of the Flowers of Lophotocarpus calycinus and Sagittaria latifolia (Alismaceae)
}

Robert B. Kaul

University of Nebraska-Lincoln

Follow this and additional works at: https://digitalcommons.unl.edu/bioscifacpub

Part of the Biology Commons, and the Botany Commons

Kaul, Robert B., "Development and Vasculature of the Flowers of Lophotocarpus calycinus and Sagittaria latifolia (Alismaceae)" (1967). Faculty Publications in the Biological Sciences. 846.

https://digitalcommons.unl.edu/bioscifacpub/846

This Article is brought to you for free and open access by the Papers in the Biological Sciences at DigitalCommons@University of Nebraska - Lincoln. It has been accepted for inclusion in Faculty Publications in the Biological Sciences by an authorized administrator of DigitalCommons@University of Nebraska - Lincoln. 


\title{
Development and Vasculature of the Flowers of Lophotocarpus calycinus and Sagittaria latifolia (Alismaceae)
}

\author{
Robert B. Kaul \\ Department of Botany, University of Nebraska, Lincoln
}

\begin{abstract}
The Alismaceae and Butomaceae are frequently cited as being among the most primitive of monocotyledonous families and their ranunculaceous characteristics are thought to indicate a close affinity with the dicotyledons. Further studies in the Alismaceae are needed in order to provide a better understanding of the actual relationships of the two families and of some developmental and morphological problems found in them.

In the Butomaceae shortening of the receptacle, reduction in carpel and stamen numbers, and developmental and meristic changes in the androecium have taken place. The flowers of two genera, Limnocharis and Hydrocleis, possess numerous stamens which develop centrifugally, while those of the other two genera, Butomus and Tenagocharis, possess nine stamens, some of them in antisepalous pairs. Stamen development in Butomus is centripetal, and the same is probably true for Tenagocharis.
\end{abstract}

The development of the bisexual flower of Lophotocarpus calycinus and of the unisexual flowers of Sagittaria latifolia has been observed. In all cases floral organs arise in acropetal succession. In L. calycinus, after initiation of the perianth, the first whorl of stamens to form consists of six stamens and is ordinarily followed by two alternating whorls of six stamens each. The very numerous carpels are initiated spirally. In the male flower of S. latifolia the androecium develops in spiral order. A few rudimentary carpels appear near the floral apex after initiation of the stamens. There are no staminodia. The female flower has a similar developmental pattern to that of Lophotocarpus except that a prominent residual floral apex is left bare of carpels. The vascular system in all flowers is semiopen, with vascular bundles passing to the floral organs in a pattern unrelated to the relative positions of those organs. The androecia of these two taxa are similar to those of some Butomaceae and relationships based on ontogeny and morphology are suggested. The gynoecia are meristically less specialized but morphologically more specialized than the gynoecia of Butomaceae.

In the Alismaceae, so far as is known, stamen development is always centripetal and paired stamens are found in at least Alisma, Sagittaria, Lophotocarpus, Limnophyton, Damasonium, and Echinodorus. The present' study has been undertaken in the expectation that more information can be brought forward toward the solution of the problems of the significance of centripetal vs. centrifugal stamen development and of paired stamens. Also, it is hoped that the study of the vasculature and of the pattern of development of the flowers in general has revealed data of phylogenetic importance.

The generic boundaries between Sagittaria and Lophotocarpus are weak, and the latter is sometimes considered to be a part of the former. The flowers of Lophotocarpus calycinus (Englm.) J. G. Sm. are either all perfect or the upper ones in an inflorescence are staminate. All of the plants examined from the one huge colony studied here had only perfect flowers. The subglobose 
receptacle is covered with hundreds of carpels each of which matures into a winged achene. Around its base are 9-18 stamens (Figures 1 and 6). The three white petals are deciduous but the three sepals persist and become appressed to the fruiting head. Sagittaria latifolia Willd. is a highly variable species found throughout much of North America. Within each inflorescence the lower flowers are usually pistillate and the upper ones staminate. Taxonomic treatments attribute perfect flowers to some specimens, but none have been examined for this study. The male flowers, each with three persistent sepals and three deciduous petals, have $20-40$ or more stamens and 2-10 rudimentary carpels (Figures 2 and 11). The female flowers, with perianths similar to those of the males, have a variable number of staminodia surmounted by hundreds of carpels borne on a receptacle somewhat flatter than that of Lophotocarpus (Figures 3, 13, and 14). The sepals remain reflexed away from the maturing fruiting head.

\section{Methods and Materials}

Specimens of Lophotocarpus calycinus were collected by the author from a large colony in a saline marsh near Lincoln. He collected Sagittaria latifolia from Nebraska, Minnesota, and Oregon localities. Other species of Sagittaria examined but not described in detail here include $S$. sagittaefolia, collected by the writer in Malaya, S. rigida from Minnesota, and S. falcata from commercial sources.

Some flowers were hand-sectioned for study while alive and the remainder were fixed in FAA. Entire developmental series were obtained by carefully dissecting the crowns of the plants to obtain inflorescences in various developmental stages. Some specimens were embedded in paraffin, sectioned, stained with safranin and fastgreen, and mounted in Clarite according to the usual schedule for such a series. Other specimens were studied without special treatment after hardening in the fixative. Still others were cleared in $\mathrm{NaOH}$, stained with safranin, and placed in xylene or $85 \%$ lactic acid. Larger, more mature flowers were sliced horizontally or longitudinally before such treatments. About 20 inflorescences of Lophotocarpus and about 30 of Sagittaria in various developmental stages were examined by these methods. Because of the enormous numbers of carpels microtome sections were frequently found to be of little value except for clarification of impressions gained from cleared materials. The cleared specimens provided excellent material with which to work and they were observed with both dark-field and brightfield microscopy.

\section{Observations}

Lophotocarpus calycinus-The flower primordium appears as a low broad mound in the axil of the developing subtending bract. When it is about $0.25 \mathrm{~mm}$ broad the sepal primordia arise in rapid succession. Shortly thereafter the petal primordia appear almost simultaneously with the first stamen primordia. The first stamen primordia appear in pairs opposite the sepals (Figure 4). Following initiation of these first six stamens six more appear, each opposite a petal or a sepal and on a slightly higher plane than the first stamens. Then the third whorl of six stamens alternate with those of the second whorl appears. These six could be interpreted as constituting three antisepalous or antipetalous pairs since none is directly opposite any perianth member (Figure 4 ). The total number of stamens in many flowers is 18 but departures from this number are common.

Following initiation of the last whorl of stamens the first carpel primordia appear on the flanks of the apex above the stamens (Figure 5). The floral apex now enters a period of great and rapid growth in breadth. New carpels are initiated acropetally and spirally from the first carpel primordia, and while the apex is broadening they appear only on the flanks. After the apex
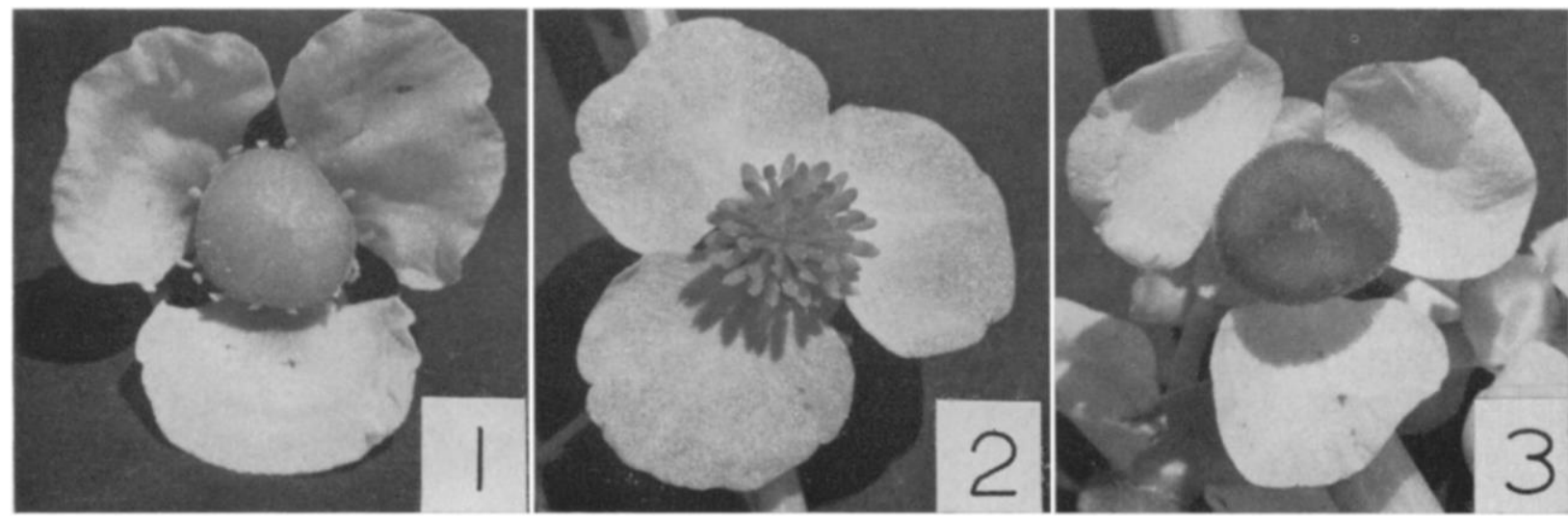

Figure 1. Flower of Lophotocarpus calycinus. Receptacle is completely covered by the carpels, X 2. | Figure 2.

Sagittaria latifolia, male flower, X 2. | Figure 3. S. latifolia, female flower. Receptacle is not completely covered by carpels, X 1.5. 
ceases its radial growth new carpels continue to be initiated acropetally until they almost cover the apex (Figure 6). By anthesis the entire floral apex is covered by carpels. After initiation of all organ primordia, when the floral primordium is about $3 \mathrm{~mm}$ broad, the sepal primordia cover the entire structure. The petal primordia remain relatively poorly developed at this stage (Figure 6). When all except the uppermost flower or two of an inflorescence have reached this stage the inflorescence axis, which is now about $2 \mathrm{~cm}$ long, begins to bolt. Few new organ primordia are initiated during this elongation in any but the uppermost flowers. Maturation of the
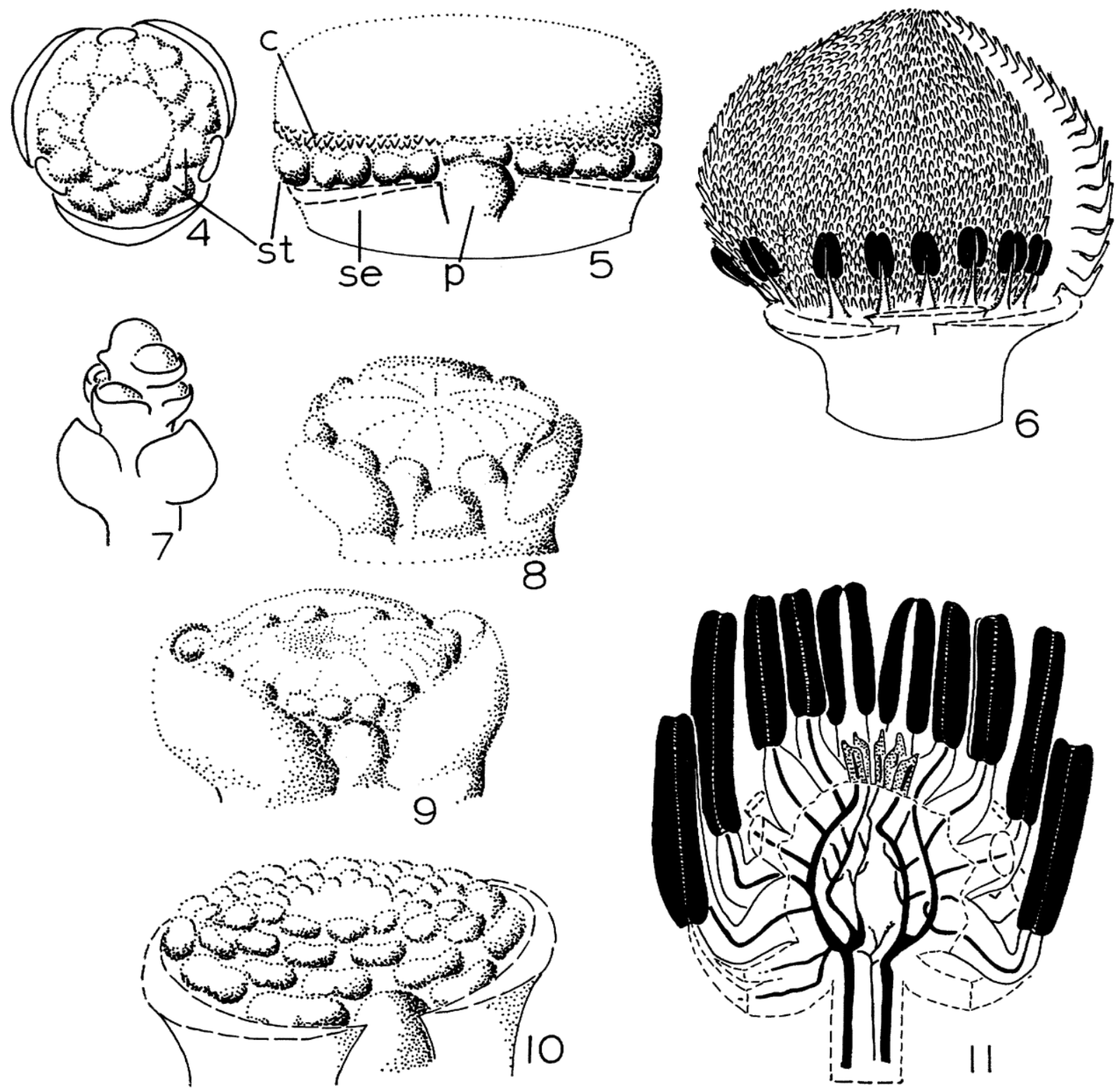

Figures 4-6. Lophotocarpus calycinus. | Figure 4. Polar view of floral apex just after, initiation of the last stamens at the beginning of carpel initiation, X 50. | Figure 5. Lateral view of floral apex later. Sepals removed. Stamens are further developed and somewhat displaced by the expansion of the apex. Carpel primordia are beginning to form along the flanks of the apex, X 45. | Figure 6. Mature flower with perianth cut away and with a wedge of the receptacle removed to show the orientation of the carpels, X 4. | Figures 711. Sagittaria latifolia. | Figure 7. Young inflorescence with floral apices developing in axils of bracts. These flowers will probably be female, X 25. | Figure 8. Floral apex of male after initiation of 12 stamen primordia, X 65. | Figure 9. Male apex after initiation of numerous stamens, showing increase in breadth of apex and growth of perianth, X 50. | Figure 10. Male floral apex just after initiation of all stamen primordia but before initiation of rudimentary carpels. Sepals removed, X 40. | Figure 11. Radial section of male flower at anthesis; perianth removed. Rudimentary carpels stippled, X 10.-c, carpel primordia; p, petal; se, sepal; st, stamen primordium. 
inflorescence is accompanied by maturation of the perianth and reproductive organs and by great increase in size of all structures. By anthesis the petal primordia have grown from $0.5 \mathrm{~mm}$ in height to $1.0 \mathrm{~cm}$ or more. The floral axis at anthesis is about $1.0 \mathrm{~cm}$ broad. The stamens mature in the same order in which they were initiated, but their whorled nature has been somewhat obscured at anthesis by the great increase in size of the floral axis and consequent displacement of stamens (Figure 6).

The vasculature of the flower is so similar to that found in the female flower of Sagittaria latifolia that the reader is referred to the illustrations of that species given here. The outer portion of the pedicel contains numerous small vascular bundles which proceed upward into the sepals and petals where they form part of the network of small veins found in those organs. In the center of the pedicel there are usually 18 bundles arranged in three series: an inner group of three large bundles, a middle group of three somewhat smaller bundles alternate with the inner ones, and an outer group of 12 still smaller bundles alternate with these six. These central bundles are parallel until they reach the lower part of the receptacle, where they become variously branched and anastomosed (cf. Figure 14). The larger branches from the first branchings proceed along the receptacular periphery where they supply each of the numerous carpels with a single bundle (cf. Figures 14 and 15). The smaller branches from the base of the receptacle proceed directly toward the top of the receptacle where they supply the uppermost carpels in a similar way (see Figure 14). Each carpel receives a single bundle from the receptacle. This bundle bifurcates with one branch proceeding into the ovule and the other continuing into the style.

After anthesis maturation of the fruits occurs within a few weeks. The carpels increase somewhat in size and become prominently winged. During this time the entire inflorescence bends down and the mature achenes are released at or below the water surface. Changes in the vascular system from anthesis to maturity of fruits are slight.

\section{Sagittaria latifolia, male flower}

The floral apex of the male flower appears as a broad low mound in the axil of the developing bract (Figure 7). By the time the bract has barely covered the floral primordium the three sepal primordia appear almost simultaneously. While they are still quite small the three alternate petal primordia arise almost simultaneously with, and slightly below, the first and lowest stamen primordia (Figure 8). The petal primordia develop slowly so that by the time the last stamen primordia are initiated the petals have barely increased in size, although the sepals have reached nearly full size (Figures 9 and 10). Just prior to and during early anthesis the petals expand to full size. The stamen primordia develop in acropetal and spiral succession, and the more vigorous the specimen the more stamens that are produced. The lowest, first-formed stamens can be interpreted as constituting three pairs of antisepalous stamens. As the stamen primordia develop across the low floral apex the first-formed stamens continue to differentiate so that by the time the last stamen primordia are formed the earlier ones have well-developed anthers. The rudimentary carpels are produced distal to the last-formed stamens and a small residual apex is left (Figure 11).

The peripheral portion of the pedicel contains numerous small bundles which enter the perianth. The central portion of the pedicel contains 12 larger bundles which enter the receptacle and branch variously, the branches proceeding upward toward the tip of the receptacle (Figure 11). From the lower portions of these branches small bundles depart into the perianth. Each stamen receives a single bundle from an upwardly progressing bundle. Each rudimentary carpel also receives a single bundle which terminates a large receptacular bundle (Figure 11).

\section{Sagittaria latifolia, female flower}

The primordium of the female flower at first appears as a broad low mound in the axil of the developing bract (Figure 7). Three sepal primordia appear almost simultaneously when the flower primordium is partly covered by the bract and before the appearance of the three alternate petal primordia. Growth of the petal primordia is slow so that by the time the flower has reached the stage shown in Figure 13 the sepal primordia are almost full-grown, the staminodia are welldeveloped, and the first carpel primordia have appeared while the petals remain relatively undifferentiated. While the perianth primordia are forming the entire floral apex broadens rapidly but there is only slight increase in relative height accompanying it. This broadening activity continues while the staminodial and carpel primordia are being initiated and even until anthesis. The staminodial primordia appear in acropetal succession and are at first most numerous near the petal primordia. More robust specimens have more staminodia than others. At anthesis the staminodia are about as long as the carpels (Figure 14) and they are yellow. Distal to the staminodia the floral apex continues to broaden and the first carpel primordia appear on the flanks or actually beneath the overhang of the receptacle (Figure 12). New carpels are initiated acropetally and spirally up the flanks and out onto the flatter distal portion of the receptacle (Figure 13). A residual apex remains at the center of the receptacle and the last-formed carpels near this area do not fully mature (Figures 3 and 14). At maturity as well as at anthesis 
the receptacle is somewhat flattened and, at least on top, slightly mounded opposite each petal (Figure 3).

The peripheral portion of the pedicel contains numerous small bundles which enter the perianth. In the center of the pedicel there are three large bundles. Just peripheral to and alternating with these are three slightly smaller bundles, and peripheral to those are 12 still smaller bundles alternating with the inner six. Upon entering the receptacle these bundles become branched and somewhat anastomosed. About onethird of the way up the receptacle these branches reunite and then branch again more or less dichotomously as they pass upward through the receptacle (Figures 14 and 15). The perianth, staminodia, and lower carpels are supplied with bundles which depart from the first branchings of the pedicellar bundles, and successively higher carpels are supplied from higher-order branchings (Figure 14). The uppermost, last-formed carpels, however, are supplied with weaker vascular bundles which depart directly from the level of first-order branching of the pedicellar bundles (Figure 15). Each carpel is served by a single bundle which leaves the receptacle and branches once within the carpel. One branch proceeds into the ovule and the other continues into the stylar beak (Figure 15). Vascular changes from anthesis to maturity are slight.
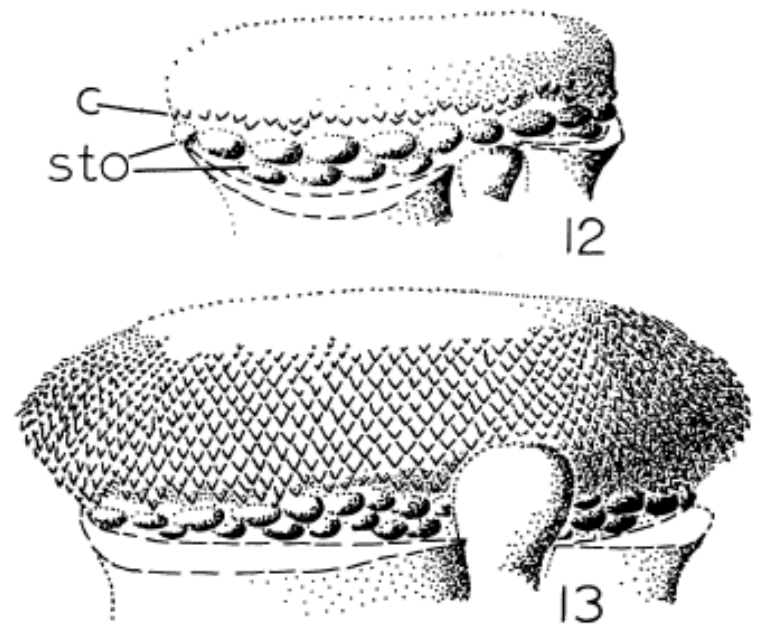

Figures 12-15. Sagittaria latifolia, female flower. | Figure 12. Floral apex after initiation of staminodial primordia and just as carpel primordia are beginning to appear, X 50. | Figure 13. Later stage, after great increase in breadth of apex and after initiation of more carpel primordia. Sepals removed, X 40. | Figure 14. Longitudinal section of flower at anthesis, showing vascular system, X 6. | Figure 15. Polar view of lower half of decapitated mature flower showing vascular system as it passes up from the pedicel and spreads out through the receptacle, $X$ 7.-c, carpel primordia; sto, staminodia.

\section{Other species of Sagittaria}

Cleared flowers of $S$. sagittaefolia L., S. rigida Pursh, and $S$. falcata Pursh show that the vascular patterns are similar to those of $S$. latifolia. The variations among these species are perhaps no greater than those found within S. latifolia. Eber's (1934) study of the development of the female flower of $S$. lancifolia $\mathrm{L}$. suggests that floral development in that species is similar to that of S. latifolia.

\section{Discussion}

The pattern of development of the androecia of these two taxa recalls in some respects those found in Alisma (Buchenau, 1857) and Butomus (Buchenau, 1857; Payer, 1857). The organs arise in centripetal order and some stamens occur in antisepalous pairs. The members of each pair ordinarily arise as separate primordia and not as a single primordium which later divides and, in that way too, are similar to the paired stamens of Butomus and Alisma. This independent origin of the
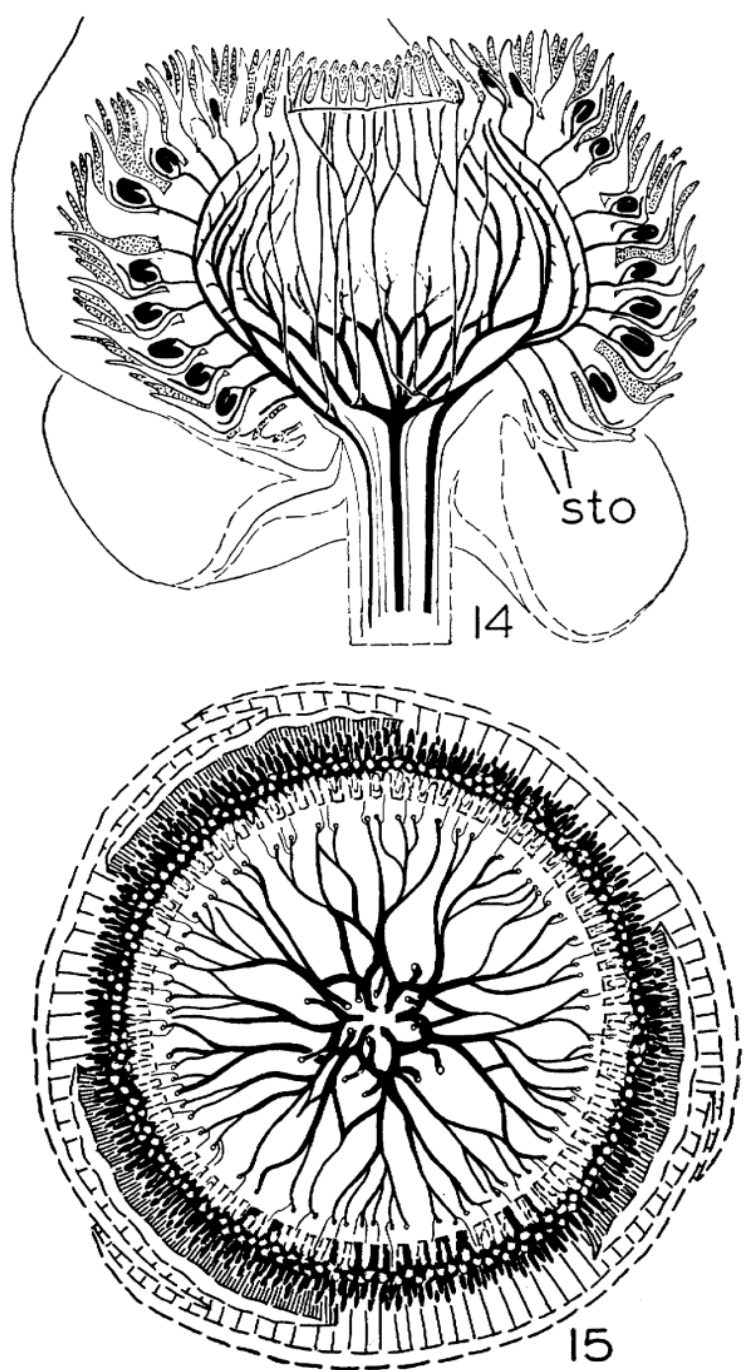
stamens does not support the views of Eichler (1875), Salisbury (1926), and others that these paired stamens are the result of phylogenetic splitting of a single stamen or its primordium. Further evidence against such an interpretation is furnished by the vascular anatomy, which shows that the members of each pair are vascularized independently from the receptacular vascular tissues and not from a single bundle which bifurcates. The writer has found a similar vascular pattern occurring in Butomus and Tenagocharis stamen pairs. No examples of branched stamens were observed in Lophotocarpus calycinus or in Sagittaria latifolia but they have been observed by Salisbury (1926) and by the writer in S. sagittaefolia. They have been interpreted by the former as evidence of phylogenetic fission of stamens. The writer is inclined to regard them as normal occasional fusions of stamens which are to be expected as slight modifications of the normal developmental pattern and thus to be without phylogenetic significance. It is likely that the alternating whorls of stamens found in Lophotocarpus and male Sagittaria flowers are the products of phylogenetic stabilization of numbers of stamens, and of their positions, in these androecia. Furthermore, it is possible that the stamen pairs are simply residual members of ancestral androecia which possessed many more stamens. Such androecia probably contained numerous spirally arranged organs which by well-known evolutionary processes became fewer in number and whorled. The male S. latifolia flower represents a stage in such a stabilization. With this interpretation the stamen pairs would not really be pairs at all but only an outer whorl of stamens. The apparently non-whorled nature of the staminodia in the female flower of S. latifolia and of at least the upper stamens in the male of that species may be relicts from the time when all stamens were spirally arranged. Further suggestion of stabilization in the androecium is the fact that no staminodia are found in Lophotocarpus or in the male S. latifolia flower, suggesting that sterilization of stamens is not now a conspicuous part of the evolution of these plants.

The pattern of development of the carpels clearly indicates that spiral arrangement of parts occurs in these taxa. In these gynoecia retention of enormous numbers of carpels is correlated with retention of the spiral arrangement of those organs. Such phenomena are well known in other families, e.g., Ranunculaceae. In these alismaceous gynoecia the configuration of the vascular system does not correlate with the arrangement of the organs. Instead, there is an almost completely open vascular system (Figures 14 and 15) supplying carpels on many radii rather than in spiral order. A similar pattern was noted by Tepfer (1953) for Ranunculus repens and by Sporne (1958) for several ranunculaceous genera. The stamens and stamen whorls in the male flower of S. latifolia are also vascularized independently of their phyllotactic position.
The vascular systems of the flowers of L. calycinus and S. latifolia, when compared with those illustrated for Clematis douglasii, Trollius europaeus, and Anemone japonica by Sporne (1958) show expected similarities. The vascular systems above the base of the receptacle are essentially open, that is, with few or no anastomoses. Each reproductive organ or its rudiment receives a single vascular bundle. Carpels and stamens, or their rudiments, are supplied from the same major receptacular trunk bundles, and all the bundles terminate in a carpel or its rudiment. Thus the morphological similarities of some taxa of both these families are paralleled by anatomical similarities.

A comparison of the vascular systems with those of the Butomaceae shows fewer obvious similarities. The androecial supply in the multistamened Butomaceae, Limnocharis and Hydrocleis, however, resembles that of the male flower of $S$. latifolia insofar as all have more or less open, dendritic systems serving numerous stamens. In Sagittaria these dendritic systems proceed upward through the receptacle whereas in Limnocharis and $\mathrm{Hy}$ drocleis they proceed outward. In all cases the firstformed stamens appear along the lower portion of the dendritic system and new ones are initiated at successively higher levels in the system. Thus in Sagittaria with the systems oriented vertically the stamens appear centripetally, while in Limnocharis and Hydrocleis with the systems oriented horizontally the stamens appear centrifugally. In Sagittaria these systems terminate in rudimentary carpels while in the Butomaceae they terminate in staminodia. In the flower of Lophotocarpus and that of female Sagittaria similar but somewhat more anastomosed dendritic systems supply both stamens or staminodia and carpels, with the carpels terminating each system. In Limnocharis and Hydrocleis the carpels, fewer by far than in Lophotocarpus and Sagittaria, are each vascularized by a single bundle derived from the receptacular vascular tissues slightly above the departure of the stamen trunk bundles and not from a dendritic system. In these two genera it is probable that phylogenetic reduction in carpel number has been accompanied by reductions in the vascular system while their androecia, having retained numerous parts, still possess a more elaborate vascular pattern.

The tendency toward shortening of the receptacle, so prominent in other genera of the family and in the Butomaceae, is not strong in Lophotocarpus and Sagittaria. Even the male flower of $S$. latifolia, which bears far fewer organs than the female, has a relatively elongate receptacle. The prominent residual floral apex of the female Sagittaria flower is a primitive feature with counterparts in all four genera of Butomaceae.

These two taxa represent advancements over their presumed butomaceous allies in their carpels, which are reduced to achenes as compared with the basically open carpels and numerous ovules of the Butomaceae. On the other hand the butomaceous gynoecia are more 
specialized meristically, being reduced to more or less constant numbers. The androecia of Butomus and Tenagocharis are slightly more advanced than those of Lophotocarpus and Sagittaria insofar as the former are reduced to nine stamens each. The androecia of Limnocharis and Hydrocleis, with their numerous spirally arranged and centrifugally developed members, are undoubtedly more primitive than those of these two plants.

The evidence presented here, in combination with that presented in taxonomic treatments, leaves little doubt that Lophotocarpus and Sagittaria are closely related and there seems to be no reason not to include both in the same genus as is sometimes done.

\section{Literature Cited}

Buchenau, F. 1857. Über die Blütenentwicklung von Alisma und Butomus. Flora 40: 241-256.

Eber, E. 1934. Karpellbau und Plazentationsverhältnisse in der Reihe der Helobiae. Flora 127: 273-330.

Eichler, A. W. 1875. Blüthendiagramme, volume 1. W. Engelmann, Leipzig.

Payer, J. B. 1857. Traite d'organogénie comparée de la fleur, volume 1. Librarie de Victor Masson, Paris.

Salisbury, E. J. 1926. Floral construction in the Helobiales. Annals of Botany 43: 459-481.

Sporne, K. R. 1958. Some aspects of floral vascular systems. Proceedings of the Linnean Society of London 169: 75-84.

Tepfer, S. S. 1953. Floral anatomy and ontogeny in Aquilegia formosa var. truncata and Ranunculus repens. University of California Publications in Botany 25: 513-648. 